\title{
INTERCALAÇÃO E FUNCIONALIZAÇÃO DA BRUCITA COM ÁCIDOS CARBOXÍLICOS
}

\author{
Fernando Wypych* e Gregorio Guadalupe Carbajal Arízaga \\ Departamento de Química, Universidade Federal do Paraná, CP 19081, 81531-990 Curitiba - PR
}

Recebido em 23/10/03; aceito em 26/8/04; publicado na web em 12/11/04

\begin{abstract}
INTERCALATION AND FUNCTIONALIZATION OF BRUCITE WITH CARBOXYLIC ACIDS. Brucite $\left(\mathrm{Mg}(\mathrm{OH})_{2}\right)$ is a structural model of several natural layered minerals as well as of synthetic layered double hydroxides (LDH). Exchange reaction studies of these compounds are well documented in the literature but surface chemical modifications, especially for brucite, are quite rare. We report the behaviour of brucite in reaction with succinic and benzoic acid in different solvents and temperatures. The compounds were analysed through X-ray diffraction (XRD) and infrared spectroscopy (FTIR). The surfaces of brucite crystals were grafted producing expansions, attributed to the arrangement of the grafted species between the layers.
\end{abstract}

Keywords: brucite; grafting; carboxylic acids.

\section{INTRODUÇÃO}

Processos de intercalação envolvendo matrizes derivadas da estrutura da brucita $\left(\mathrm{Mg}(\mathrm{OH})_{2}\right)$, especialmente em hidróxidos duplos lamelares (HDL), são amplamente discutidos na literatura ${ }^{1-4}$. As matrizes dos HDL estão intimamente ligadas à estrutura da brucita, onde íons magnésio são coordenados octaedricamente a grupamentos hidroxila. Esses octaedros estão ligados entre si através das arestas, obtendo-se lamelas "bidimensionais", que são ligadas umas às outras através de forças de van der Waals e ligações de hidrogênio.

Os HDL possuem uma formulação genérica do tipo $\left[\mathrm{M}^{+2}{ }_{1-x} \mathrm{M}^{+3}{ }_{x}\right.$ $\left.(\mathrm{OH})_{2}\right]^{\mathrm{x}+}\left(\mathrm{A}^{\mathrm{m}-}\right)_{\mathrm{x} / \mathrm{m}} \cdot \mathrm{nH}_{2} \mathrm{O}$, onde $\mathrm{M}^{+3}$ e $\mathrm{M}^{+2}$ representam cátions passíveis de ocuparem sítios octaédricos e $\mathrm{A}^{\mathrm{m}-\mathrm{-}}$ representa um ânion de carga m-. Nesses compostos, o cátion trivalente substitui isomorficamente um cátion divalente da estrutura do hidróxido, criando cargas residuais que são compensadas com a intercalação de ânions hidratados. As forças que mantêm esta estrutura coesa são atribuídas às forças eletrostáticas entre as lamelas positivamente carregadas e os ânions, além de ligações de hidrogênio estabelecidas entre as moléculas de água co-intercaladas e grupamentos hidroxila das lamelas.

Matrizes contendo diferentes metais ou mesmo metal com diferentes estados de oxidação podem também produzir compostos semelhantes aos HDL ${ }^{5,6}$. Apesar de muitos artigos terem sido publicados reportando reações de troca iônica dos $\mathrm{HDL}^{1-3}$ e compostos com estruturas semelhantes aos $\mathrm{HDL}^{5,6}$, os quais possuem estruturas adequadas para funcionalização, poucos são os trabalhos que abordam essa classe de reações ${ }^{1,7-9}$.

Além dos HDL, os hidroxisais lamelares (HSL) também possuem estruturas adequadas para serem submetidos a reações de intercalação e funcionalização. Nesses compostos, parte dos grupamentos hidroxila são substituídos por ânions orgânicos ou inorgânicos, produzindo compostos neutros com a formulação genérica $\mathrm{M}^{+2}(\mathrm{OH})_{2}$. ${ }_{x}\left(\mathrm{~A}^{-}\right)_{\mathrm{x}} \cdot \mathrm{nH}_{2} \mathrm{O}^{10-14}$. Esses compostos possuem íons interlamelares trocáveis, os quais podem gerar compostos pilarizados através de um processamento posterior ${ }^{15,16}$.

Apesar da brucita possuir superfícies interlamelares reativas e estrutura lamelar, com espaçamento basal de $4,8 \AA$, da qual são deri-

*e-mail: wypych@quimica.ufpr.br vadas as estruturas tantos dos HDL quanto dos HSL, poucas referências citam essa matriz nas reações de funcionalização. A principal razão baseia-se no fato de que as ligações que mantêm a estrutura coesa limitam o número de moléculas que podem penetrar nos espaçamentos interlamelares e serem submetidas à reação ${ }^{17}$. Reações de funcionalização foram reportadas recentemente para outros hidróxidos simples lamelares ${ }^{8,18,19}$ e HDL $^{1,14,20,21}$.

Baseado nesse fato, o objetivo do presente trabalho é a descrição do comportamento da brucita frente à reação com ácidos succínico e benzóico, que possuem diferentes forças ácidas, em diferentes solventes e condições experimentais.

\section{PARTE EXPERIMENTAL}

A brucita foi a matriz lamelar testada frente a sua reatividade com ácido succínico (dicarboxílico) e ácido benzóico (monocarboxílico), em diferentes temperaturas e solventes. Nos ensaios foram utilizados: $\mathrm{MgSO}_{4} \cdot 7 \mathrm{H}_{2} \mathrm{O}$ (Reagen), solução $30 \%$ de $\mathrm{NH}_{3}(\mathrm{Nu}-$ clear), uréia (Carlo Erba), $\mathrm{Mg}\left(\mathrm{NO}_{3}\right)_{2} \cdot 6 \mathrm{H}_{2} \mathrm{O}$ (Vetec), ácido benzóico (Merkc) e ácido succínico (Riedel).

\section{Síntese da brucita}

A síntese da matriz foi realizada por precipitação segundo o procedimento descrito na literatura ${ }^{17}$, dissolvendo-se $\mathrm{MgSO}_{4} .7 \mathrm{H}_{2} \mathrm{O}$ $(10,605 \mathrm{~g}, 0,0425 \mathrm{~mol})$ em $50 \mathrm{~mL}$ de água destilada. Sob agitação magnética, gotejou-se $11,5 \mathrm{~mL}$ de solução $30 \%$ de $\mathrm{NH}_{3}$ obtendo o $\mathrm{pH}=11$ na suspensão final. Manteve-se a agitação por $24 \mathrm{~h}$ à temperatura ambiente e, em seguida, o material foi lavado três vezes com $25 \mathrm{~mL}$ de água destilada, centrifugando-se o gel a $4500 \mathrm{rpm}$ por 5 min. Considerando-se a constante de produto de solubilidade da brucita $\left(1,8 \times 10^{-11}\right)$, o pH final da suspensão e o volume da solução de lavagem, as perdas por solubilização podem ser consideradas desprezíveis. O material foi seco a $60^{\circ} \mathrm{C}$ por $24 \mathrm{~h}$.

\section{Tratamento hidrotérmico da brucita}

Logo após a adição da solução aquosa de $\mathrm{NH}_{3}$ na preparação da brucita, $15 \mathrm{~mL}$ da suspensão foram transferidos para um reator de teflon de $20 \mathrm{~mL}$ com camisa de aço, o qual foi aquecido a $160{ }^{\circ} \mathrm{C}$ por 21 h. Após esfriamento, o material resultante foi lavado e seco da mesma maneira que o produto por precipitação direta. 


\section{Tentativas de modificação da brucita}

Para toda a série de ensaios a seguir foi empregada a brucita obtida por precipitação direta, pois considerou-se que a submetida a tratamento hidrotérmico possui cristais maiores, como sugerem as reflexões estreitas no DRX (Figura 1b). Portanto, seria mais fácil introduzir moléculas hóspedes em cristais menores.

Cinco métodos experimentais foram testados, a saber: 1) a precipitação de íons magnésio com solução $30 \%$ de $\mathrm{NH}_{3}$ na presença de ácido carboxílico, 2) a agitação sob aquecimento de uma suspensão de brucita recém preparada e o ácido carboxílico, em meio aquoso e em outros solventes, 3) ou o tratamento da suspensão anterior com o ácido em um reator térmico de teflon com camisa de aço, 4) o aquecimento de uma pastilha composta de brucita e ácido carboxílico prensada a $6 \mathrm{t} / \mathrm{cm}^{2}(\mathrm{re}-$ ação no estado sólido), 5) um último procedimento envolvendo a trituração de uma mistura de nitrato de magnésio hexaidratado, uréia e ácido carboxílico em um cadinho de porcelana, ao qual são acrescentados $2 \mathrm{~mL}$ de água para auxiliar a homogeneização. Nessa etapa, observouse a formação de uma pasta com um aspecto de material fundido, deno-

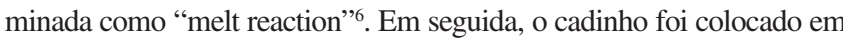
estufa e agitado esporadicamente. Os processos e condições de cada ensaio estão apresentados na Tabela 1.

Os produtos resultantes dos ensaios da brucita com ácido succínico foram lavados com $30 \mathrm{~mL}$ de água, enquanto que para todos os outros, $25 \mathrm{~mL}$ de etanol. A lavagem e secagem foram realizadas como descrito no procedimento de lavagem da matriz.

\section{INSTRUMENTAL}

Foram empregadas as técnicas de difratometria de raios-X (DRX) e espectroscopia vibracional na região do infravermelho (IV) para monitorar a eficácia das reações, tanto da síntese da brucita original, quanto dos seus compostos derivados com ácidos orgânicos. Os difratogramas de raios- $\mathrm{X}$ foram obtidos em filmes dos materiais so- bre porta-amostras de vidro neutro, utilizando-se um difratômetro Shimadzu, XRD-6000, operando com radiação $\mathrm{CuK}_{\alpha}=1,5418 \AA$ $(40 \mathrm{kV}$ e $30 \mathrm{~mA})$ e velocidade de varredura de $1 \% \mathrm{~min}$. As medidas de IV foram realizadas num equipamento Bio-Rad, FTS 3500GX, através do uso de pastilhas de $\mathrm{KBr}$ (Merck), acumulação de 16 medidas e resolução de $2 \mathrm{~cm}^{-1}$.

\section{RESULTADOS E DISCUSSÃO}

\section{Brucita}

Os difratogramas de raios-X da Figura 1 correspondem ao hidróxido de magnésio, preparado pelo método de precipitação direta (a) e tratamento hidrotérmico (b). Como esperado, o composto submetido a tratamento hidrotérmico apresentou maior cristalinidade, concordando com os estudos comparativos da estrutura do hidróxido de magnésio obtida por diferentes vias, reportados por Henrist e colaboradores ${ }^{22}$.

Os difratogramas de raios-X foram comparados na base de dados do JCPDS $^{23}$ e identificados como sendo da estrutura da brucita, ficha 44-1482. No espectro no infravermelho (Figura 2a) destaca-se a banda do estiramento do grupamento $\mathrm{OH}$ ligado ao magnésio em $3699 \mathrm{~cm}^{-1}$, em concordância com dados da literatura ${ }^{24,25}$. As bandas extras observadas no espectro da brucita podem ser interpretadas como descrito a seguir: $1630 \mathrm{~cm}^{-1}$ (água adsorvida/absorvida/coordenada), banda larga em 1255 e $925 \mathrm{~cm}^{-1}$ (ions amônio provenientes do agente precipitante), banda em $1360 \mathrm{~cm}^{-1}$ (íons carbonato, provenientes do ar) e banda larga em $1120 \mathrm{~cm}^{-1}$ (íon sulfato livre, proveniente do sal de magnésio) ${ }^{26}$.

\section{Funcionalização da brucita com ácido succínico}

Ácido succínico em meio aquoso

A espectroscopia no IV foi a primeira técnica empregada para caracterização de todos os materiais obtidos nos ensaios deste traba-

Tabela 1. Condições dos ensaios realizados com a brucita

\begin{tabular}{|c|c|c|c|c|c|c|c|}
\hline Ensaio & $\begin{array}{l}\text { Massa (g) } \\
\text { de brucita }\end{array}$ & $\begin{array}{l}\text { Massa (g) } \\
\text { de ácido }\end{array}$ & $\begin{array}{c}\text { Relação } \\
\text { molar } \\
\text { brucita/ácido }\end{array}$ & $\begin{array}{l}\text { Volume }(\mathrm{mL}) \\
\text { de solvente }\end{array}$ & $\begin{array}{l}\text { Método de } \\
\text { preparação }\end{array}$ & $\begin{array}{l}\text { Temp. } \\
\left({ }^{\circ} \mathrm{C}\right)\end{array}$ & $\begin{array}{l}\text { Tempo } \\
\text { (h) }\end{array}$ \\
\hline E1 & $4,924^{\mathrm{a}}$ & 0,5905 AS & $1^{\mathrm{a}}: 0,25$ & 15 (água) & $\mathrm{pp}$ & $a m b$ & $15 \mathrm{~min}$ \\
\hline E2 & 0,15 & 0,1519 AS & $1: 0,5$ & 25 (água) & agitação & 40 & 48 \\
\hline E3 & 0,15 & 0,0790 AS & $1: 0,25$ & 25 (água) & agitação & 40 & 48 \\
\hline E4 & 0,15 & 0,0380 AS & $1: 0,125$ & 25 (água) & agitação & 40 & 48 \\
\hline E5 & 0,09 & 0,0914 AS & $1: 0,5$ & 15 (água) & térmico & 160 & 20 \\
\hline E6 & 0,09 & 0,0456 AS & $1: 0,25$ & 15 (água) & térmico & 160 & 20 \\
\hline E7 & 0,09 & $0,0228 \mathrm{AS}$ & $1: 0,125$ & 15 (água) & térmico & 160 & 24 \\
\hline E8 & 0,15 & 0,0759 AS & $1: 0,25$ & 25 (acetona) & agitação & 50 & 120 \\
\hline E9 & 0,15 & 0,0759 AS & $1: 0,25$ & 25 (i-butanol) & agitação & 50 & 120 \\
\hline E10 & 0,15 & 0,0759 AS & $1: 0,25$ & 25 (acetona) & térmico & 100 & 4 \\
\hline E11 & 0,15 & 0,0759 AS & $1: 0,25$ & 25 (i-butanol) & térmico & 150 & 72 \\
\hline E12 & 0,15 & - & - & 25 (i-butanol) & térmico & 150 & 72 \\
\hline E13 & $1,2315^{\mathrm{a}}$ & $0,3053 \mathrm{AB}$ & $1^{\mathrm{a}}: 0,5$ & 50 (água) & $\mathrm{pp}$ & $\mathrm{amb}$ & $15 \mathrm{~min}$ \\
\hline E14 & 0,2598 & $0,5442 \mathrm{AB}$ & $1: 1$ & 25 (i-butanol) & agitação & 60 & 21 \\
\hline E15 & 0,2598 & $0,5442 \mathrm{AB}$ & $1: 1$ & 25 (tolueno) & agitação & 60 & 21 \\
\hline E16 & 0,2598 & $0,5442 \mathrm{AB}$ & $1: 1$ & 25 (DMSO) & agitação & 60 & 21 \\
\hline E17 & 0,1 & $0,2094 \mathrm{AB}$ & $1: 1$ & $-\mathrm{b}$ & R.E.S. & 120 & 1 \\
\hline E18 & 0,1 & $0,2094 \mathrm{AB}$ & $1: 1$ & $-^{\mathrm{b}}$ & R.E.S. & 120 & 10 \\
\hline E19 & 0,1 & $0,2094 \mathrm{AB}$ & $1: 1$ & $-^{\mathrm{b}}$ & R.E.S. & 120 & 72 \\
\hline E20 & 0,1 & $0,1047 \mathrm{AB}$ & $1: 0,5$ & $-{ }^{b}$ & R.E.S. & 120 & 72 \\
\hline E21 & 0,05 & $0,2094 \mathrm{AB}$ & $1: 2$ & — $^{\mathrm{b}}$ & R.E.S. & 120 & 72 \\
\hline E22 & $0,8796^{c}$ & $0,4189 \mathrm{AB}$ & $1^{\mathrm{c}}: 0,77$ & 2 (água) & Fusão & 110 & 5 \\
\hline
\end{tabular}

a precipitação a partir de $\mathrm{MgSO}_{4} \cdot 7 \mathrm{H}_{2} \mathrm{O} ;{ }^{\text {b }}$ pastilha obtida por pressão dos reagentes a $6 \mathrm{t} / \mathrm{cm}^{2}$; ${ }^{\text {c }}$ fusão a partir de $\mathrm{Mg}\left(\mathrm{NO}_{3}\right) \cdot 6 \mathrm{H}_{2} \mathrm{O}$ com 0,1030 g de uréia; $\mathrm{AS}$ = ácido succínico; $\mathrm{AB}$ = ácido benzóico; $\mathrm{DMSO}=$ dimetil sulfóxido; pp = precipitação; R.E.S. = reação no estado sólido; amb = ambiente. 


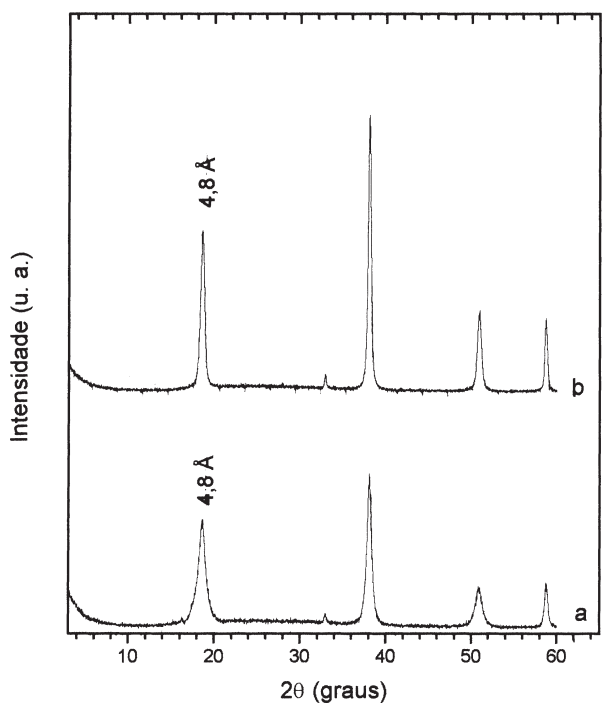

Figura 1. Difratogramas de raios-X da brucita obtida por precipitação direta (a) e submetida a tratamento hidrotérmico (b)

lho, já que por comparação direta com o espectro da brucita seria evidente alguma modificação química na estrutura lamelar. Para os materiais tratados com ácido succínico em meio aquoso, por três diferentes métodos (E1 a E7), observou-se que os respectivos espectros eram iguais ao da matriz mineral, sem a presença de banda característica do ácido carboxílico ou do correspondente sal. Com isto se deduz que a brucita não foi quimicamente modificada (espectros não mostrados).

\section{Ácido succínico: agitação em acetona e isobutanol}

Os espectros no IV dos materiais resultantes dos ensaios 8 e 9 (Figuras $2 \mathrm{~b}$ e c) apresentam duas bandas de interesse observadas em $1577 \mathrm{~cm}^{-1}\left(v_{\mathrm{a}} \mathrm{COO}^{-}\right)$e $1427 \mathrm{~cm}^{-1}\left(\mathrm{v}_{\mathrm{s}} \mathrm{COO}^{-}\right)$, ausentes no espectro da matriz (Figura 2a). A separação entre estas duas bandas é um indicativo do tipo de coordenação do ânion carboxilato com o cátion magnésio. Neste caso, o $\Delta v=\left(v_{\mathrm{a}}-\mathrm{v}_{\mathrm{s}}\right)=150 \mathrm{~cm}^{-1}$ gerado é um valor maior que o observado para o succinato de sódio, $129 \mathrm{~cm}^{-1}{ }^{1}$. Essa

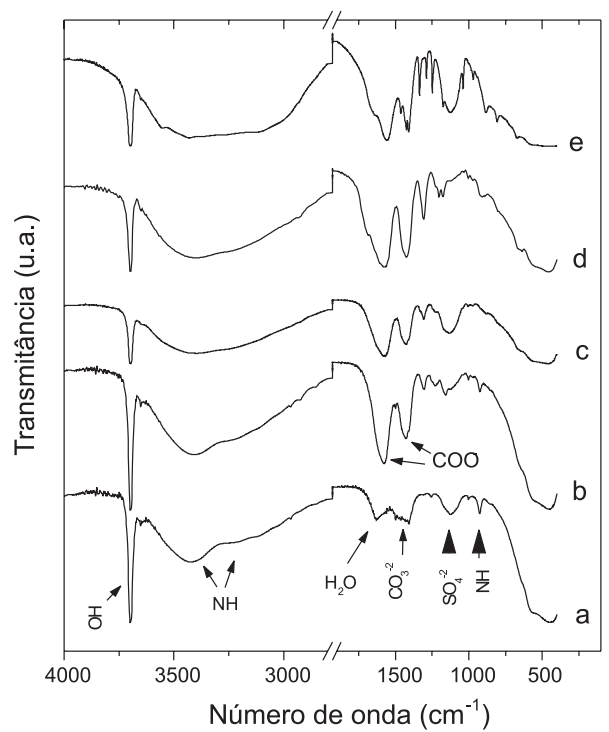

Figura 2. Espectros no infravermelho da brucita obtida por precipitação direta (a); após agitação com ácido succínico em acetona (b) e isobutanol (c) e sob tratamento térmico em acetona $(d)$ e isobutanol (e) variação é característica do íon carboxilato ligado a um cátion da lamela através de um átomo de oxigênio ${ }^{26}$.

Aproximadamente $0,3 \mathrm{~g}$ deste produto foram lavados 3 vezes com $30 \mathrm{~mL}$ de água destilada e centrifugados a $4500 \mathrm{rpm}$ por $5 \mathrm{~min}$. No espectro de IV desapareceram as bandas próximas a $1500 \mathrm{~cm}^{-1}$ atribuídas ao ânion carboxilato, confirmando assim a hidrólise do material resultante da funcionalização das superfícies externas da brucita com o íon succinato (espectro não mostrado).

Embora os espectros no IV evidenciem a presença de matéria orgânica, os difratogramas de raios-X mostram que a estrutura da brucita não sofreu alterações no espaçamento basal (Figuras $3 a$ e b). Este fato sugere que a modificação ocorre nas superfícies externas dos cristais da brucita. Isto pode ser confirmado também pela banda estreita em $3695 \mathrm{~cm}^{-1}$ atribuída a grupos $\mathrm{OH}$ livres, que sofre pequena alteração na sua intensidade, evidenciando que os grupamentos hidroxila superficiais participaram da reação com o ácido carboxílico.

As reflexões no difratograma de raios- $\mathrm{X}$ do material tratado com isobutanol diminuem de intensidade, o que representa uma perda de cristalinidade (Figura 3b).

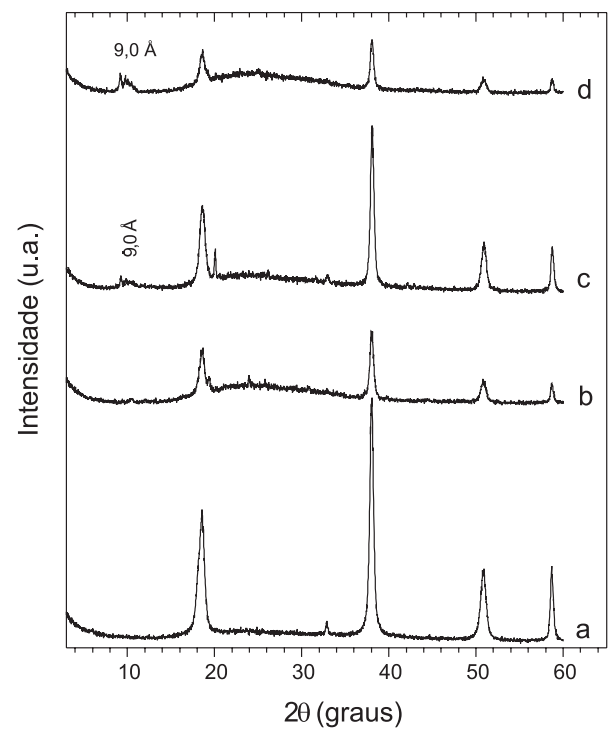

Figura 3. Difratogramas de raios- $X$ da brucita agitada com ácido succínico em acetona (a);e isobutanol (b) e sob tratamento térmico em acetona (c) e isobutanol $(d)$

\section{Ácido succínico: processo solvotérmico}

Nos espectros no IV dos materiais resultantes dos ensaios $10 \mathrm{e}$ 11 são notáveis as bandas características dos íons carboxilato (Figuras $2 \mathrm{~d}$ e e). Para descartar que as novas bandas fossem causadas pela presença de isobutanol, foi realizado um teste (E12) envolvendo o contato direto da brucita com o solvente. O espectro no IV (não mostrado) revelou que o isobutanol não altera a estrutura da brucita nas condições utilizadas $\left(150^{\circ} \mathrm{C}, 72 \mathrm{~h}\right)$.

A banda atribuída a $v_{\mathrm{s}} \mathrm{COO}^{-}$dos materiais sob tratamento térmico em acetona (E10) e isobutanol (E11) está posicionada em $1425 \mathrm{~cm}^{-1}$. Já no caso do estiramento assimétrico do referido grupamento, a banda se desloca a $1573 \mathrm{~cm}^{-1}$ para o produto tratado em acetona, e em $1561 \mathrm{~cm}^{-1}$, para o tratado em isobutanol, obtendo-se os respectivos valores de $\Delta v$ de 148 e $136 \mathrm{~cm}^{-1}$. Pode-se dizer que, nas duas situações, os íons carboxilato estão ligados à lamela através de um átomo de oxigênio, pois os valores de $\Delta v$ são maiores do que o observado para o succinato de sódio $\left(129 \mathrm{~cm}^{-1}\right)$. Um fato interessante nos espectros no IV é o surgimento de ombros nas bandas referentes ao $v_{a}\left(\mathrm{COO}^{-}\right)$em números de onda maiores $\left(1685 \mathrm{~cm}^{-1}\right.$ para E10 e 
$1635 \mathrm{~cm}^{-1}$ para E11), evidenciando uma ligação mais forte da fração orgânica com a matriz mineral ${ }^{1}$.

Nos difratogramas de raios-X dos dois materiais (Figuras $3 \mathrm{c}$ e d), evidencia-se a formação de uma reflexão de baixa intensidade correspondente a uma nova fase cristalina com distância basal de 9 $\AA$, em concordância com espaçamentos basais reportados da intercalação do íon succinato em compostos lamelares ${ }^{27,28}$. O incremento nas distâncias dos espaçamentos basais de $4,2 \AA(9-4,8)$ é próximo do diâmetro de van der Waals da cadeia alifática $(3,9 \AA)^{29}$ orientada paralelamente às lamelas da brucita. Considerando-se que somente um átomo de oxigênio de cada carboxilato interage com a lamela da brucita (informação gerada por IV), é provável que esse íon esteja intercalado com um pequeno ângulo de inclinação em relação à lamela, deixando um átomo de oxigênio livre. (Figura 4)

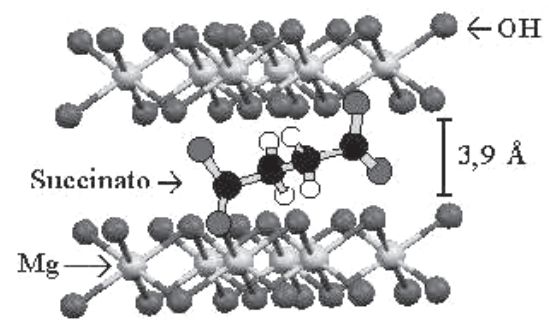

Figura 4. Arranjo do íon succinato entre as lamelas da brucita

\section{Funcionalização da brucita com ácido benzóico}

\section{Precipitação em presença de ácido benzóico}

O material resultante da precipitação direta da brucita em presença de ácido benzóico (E13) resultou na brucita não funcionalizada, como evidenciado pelo espectro no IV e no difratograma de raios-X (não mostrados).

\section{Ácido benzóico em diferentes solventes}

Nos espectros no IV dos produtos dos ensaios 14 a 16, (Figuras $5 b$, c e d) observa-se que a banda estreita em $3699 \mathrm{~cm}^{-1}$ atribuída aos estiramentos dos grupamentos hidroxila da brucita (Figura 5a) diminui de intensidade para os produtos obtidos em isobutanol, tolueno e

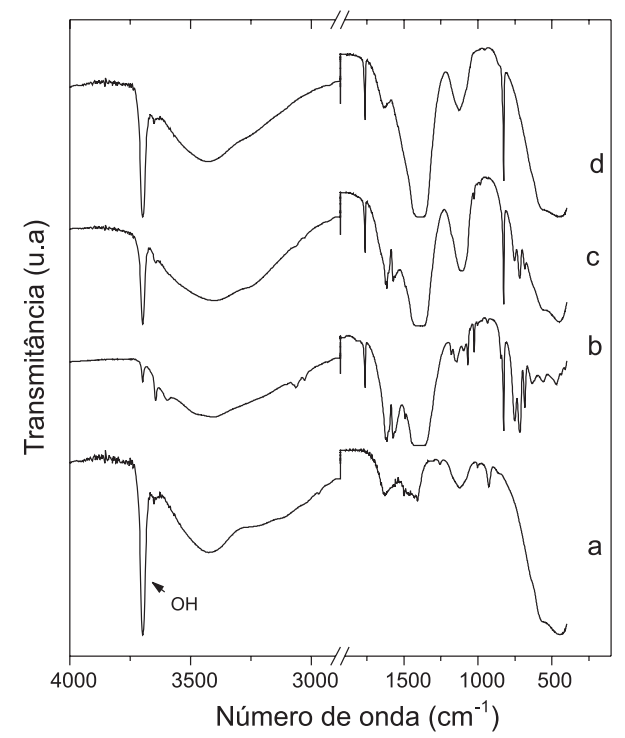

Figura 5. Espectros no infravermelho da brucita obtida por precipitação direta (a) e após agitação com ácido benzóico em isobutanol (b), tolueno (c) e DMSO (d) dimetilsulfóxido, sendo o fenômeno mais evidente para o primeiro solvente. À medida que os grupamentos hidroxila tendem a ser eliminados, surgem duas bandas: em $1614 \mathrm{~cm}^{-1}$ das flexões dos $\mathrm{C}=\mathrm{C}$ aromáticos e em $1573 \mathrm{~cm}^{-1}$ dos estiramentos assimétricos do $\mathrm{COO}^{-}$. Os estiramentos simétricos dos íons carboxilato são observados em $1400 \mathrm{~cm}^{-1}$, cuja banda teve o respectivo sinal estourado na medição realizada.

Nos espectros de IV dos produtos dos ensaios 14 e 15, a variação entre as bandas atribuídas ao $v_{\mathrm{a}}(\mathrm{COO}-)$ e $v_{\mathrm{s}}(\mathrm{COO}-)$ do íon benzoato interlamelar foi de $173 \mathrm{~cm}^{-1}$. Este desdobramento é maior que o valor de referência de $136 \mathrm{~cm}^{-1}$ obtido para o benzoato de sódio $^{30}$, portanto conclui-se que o ácido benzóico se liga às lamelas da brucita através de um átomo de oxigênio (coordenação monodentada $)^{26}$.

Nos difratogramas de raios-X, observa-se que os espaçamentos interlamelares da brucita tratada em dimetilsulfóxido (E16) não foram alterados (Figura 6c), evidenciando reações nas superfícies externas dos cristais conforme sugere o espectro da Figura 5d.

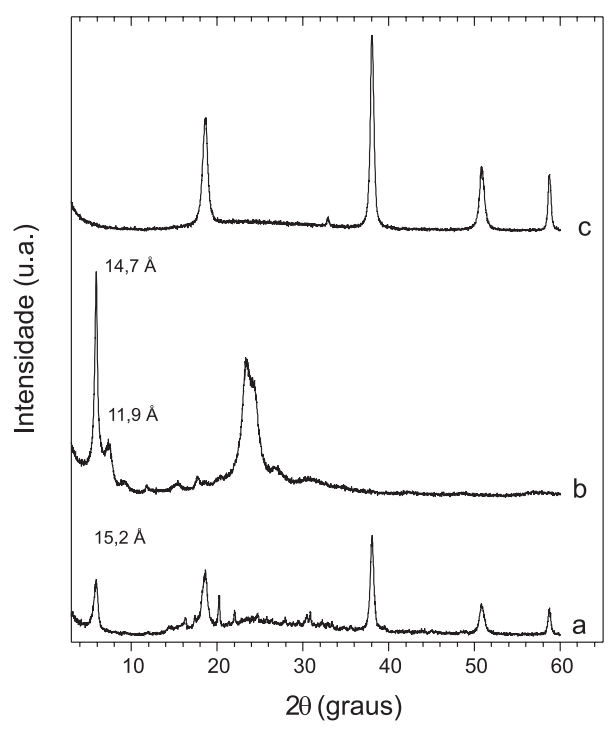

Figura 6. Difratogramas de raios-X da brucita agitada com ácido benzóico em tolueno (a), isobutanol (b) e DMSO (c)

O ácido benzóico é mais facilmente inserido entre as lamelas da brucita quando a reação se processa em isobutanol. O difratograma de raios- $\mathrm{X}$ do produto do ensaio 14 (Figura 6b), evidencia a formação de um composto principal com distância basal de 14,7 Å, além da presença de uma outra reflexão de menor intensidade com $\mathrm{d}=$ $11,9 \AA$ Os dois tipos de espaçamentos formados devem-se a diferentes orientações dos íons orgânicos entre as lamelas da brucita. A reação em tolueno produz um composto com uma distância basal de 15,2 A (Figura 6a). No caso da intercalação do íon benzoato no HDL de Mg-Al, espaçamentos basais de 15,4 $\AA$ são observados ${ }^{31}$. Em HDL de $\mathrm{Zn}-\mathrm{Cr}, \mathrm{Zn}-\mathrm{Al}$ e $\mathrm{Mg}-\mathrm{Al}^{32}$, espaçamentos da ordem de 15 a $15,5 \AA$ foram reportados, embora Prevot e colaboradores ${ }^{1}$ tenham obtido HDL de Zn-Al com espaçamento basal de 14,4 $\AA$. Nem todos os pesquisadores concordam no que se refere à posição dos íons benzoato entre as lamelas: Meyn e colaboradore ${ }^{32}$ propõem uma monocamada da fase orgânica, enquanto Hsue e Chen ${ }^{33}$ sugerem camadas duplas. A diferenciação entre as intercalações na forma de mono e duplas camadas depende do volume do cátion e da carga da lamela por unidade de área.

A intercalação de derivados simples do ácido carboxílico também forma materiais com espaçamentos basais semelhantes. Hsue e $\mathrm{Chen}^{33}$ reportam uma distância de $15 \AA$ no produto da intercalação 
do para-aminobenzoato em HDL de Mg-Al, e O'Hare e colaboradores $^{34}$ obtiveram $15,1 \AA$ ao inserir o íon tereftalato em HDL de Li-Al.

A distância entre o carbono do grupo carboxílico e o carbono em posição para no ácido benzóico é de $4,3 \AA^{32}$, sendo que este valor concorda com a distância calculada para a referida molécula utilizando-se o programa de modelagem molecular Hyperchem $6^{35}$. Considerando-se a distância entre o carbono carboxílico até o hidrogênio em posição para, o valor calculado aumenta para $5,3 \AA$. Se o átomo de oxigênio do ácido benzóico é ligado à lamela ocupando uma posição de um oxigênio da brucita, a separação entre as lamelas será função da distância entre o carbono carboxílico e o hidrogênio em posição para. Considerando duplas camadas $(5,3$ x 2=10,6 $\mathrm{A})$ (Figura 7a), somada à distância basal da brucita $(4,8 \AA)$, corresponderia a uma distância basal de $15,4 \AA$. Um espaçamento ligeiramente menor é fácil de explicar, considerando que um íon benzoato não necessariamente se posiciona exatamente na direção de outro da lamela adjacente (Figura 7b). a)

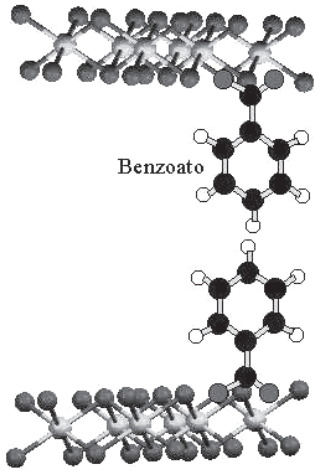

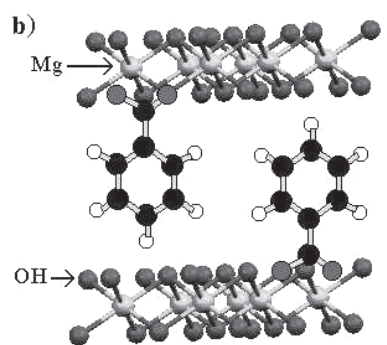

Figura 7. Disposição dos íons benzoato entre as lamelas da brucita com pequeno desvio da perpendicularidade, gerando um aumento do espaçamento basal de 10,6 $\mathrm{A}(d=15,4 \AA)$ (a) e menor que 10,6 $(d<15,4$ A) (b)

\section{Reações no estado sólido}

Observa-se na Figura 8, que o difratograma do material preparado com relação molar 1:1 sob aquecimento por $1 \mathrm{~h}$ (E17) apresenta uma reflexão com espaçamento basal de 14,3 Å (Figura 8a). No entanto, existe uma série de reflexões que começam a aparecer em 9,7 Å, que são fases intermediárias do processo, de tal forma que após 10 h de reação (E18) predomina a reflexão do espaçamento de 14,4 $\AA$ (Figura 8b). Neste ponto surge um novo espaçamento basal de 17,6 ̊, variação compatível com a adição do diâmetro de van der Waals da molécula de água (cerca de $3 \AA$ A). Portanto, a temperatura de fusão do ácido benzóico de $120{ }^{\circ} \mathrm{C}$ empregada na reação por $10 \mathrm{~h}$ não é suficiente para retirar as moléculas de água coordenadas.

Após 72 h de reação (E19), o espaçamento basal de 17,6 Å desaparece e resta o de $14,4 \AA$ (Figura 8c). No padrão de DRX da Figura 8b são identificadas as reflexões correspondentes ao benzoato de magnésio (ficha 01-0012 do JCPDS ${ }^{23}$ ). As reflexões de maior intensidade (14,4 e $5,9 \AA$ Å) ajudam a identificar a formação do benzoato de magnésio nos outros ensaios realizados no estado sólido (E17 a E19, Figura 8). Coincidentemente, o valor do espaçamento basal do benzoato de magnésio é semelhante aos valores característicos da monocamada de íons benzoato em estruturas de alguns HSL ${ }^{14}$. Este espaçamento basal corresponde também à formação de uma camada dupla de compostos aromáticos naqueles materiais lamelares cujas lamelas são folhas de octaedros ${ }^{14,36}$. Contudo, a reflexão em 5,9 Å define a formação do benzoato de magnésio e não o produto da reação topotática esperada.

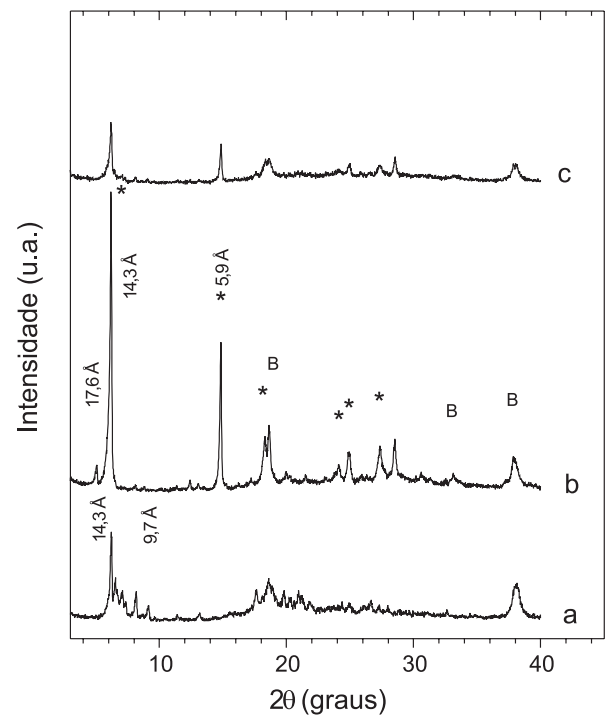

Figura 8. Difratogramas de raios-X dos produtos da reação em estado sólido da brucita com ácido benzóico, relação molar 1:1, tratados a $120{ }^{\circ} \mathrm{C}$ por 1 $h(a), 10 h(b)$ e $72 h(c)\left(^{*}=\right.$ reflexões do benzoato de magnésio; $B=$ reflexões da brucita)

Os ensaios 20 e 21 confirmam que uma relação molar brucita/ ácido benzóico maior ou menor que a empregada no ensaio 19 (1:1) também leva à formação de benzoato de magnésio (difratogramas não mostrados).

Para todos os materiais obtidos por reação no estado sólido (E17 a E21), os espectros no IV (não mostrados) apresentam bandas características do íon carboxilato em 1414 e 1551-1570 $\mathrm{cm}^{-1}$, e das hidroxilas ligadas ao magnésio em cerca de $3700 \mathrm{~cm}^{-1}$.

\section{Fusão do ácido benzóico na presença de uréia e nitrato de magnésio hexaidratado}

O padrão de difração de raios-X do produto do ensaio 22 (Figura 9) é característico de um composto lamelar ${ }^{37}$, já que a reflexão do plano basal $(14,8 \AA$ A ) aparece com mais três reflexões harmônicas (indicadas entre parêntesis na Figura 9). O produto apresenta uma fase cristalina predominante, todavia existem reflexões de baixa intensidade características do benzoato de magnésio (marcadas com asteriscos na Figura 9).

No espectro no IV (Figura 10) é observada uma banda intensa e estreita em $1651 \mathrm{~cm}^{-1}$ atribuída ao estiramento $\mathrm{C}=\mathrm{O}^{38}$, provavelmente devida à presença de ácido benzóico. Embora esta espécie não tenha sido detectada no difratograma de raios- $\mathrm{X}$, a mesma poderia estar dispersa nas galerias interlamelares formadas por pilares de ânion benzoato, pois é clara a presença do ânion carboxilato no produto, devido às bandas características em $1558 \mathrm{~cm}^{-1}\left(v_{\mathrm{a}}\right)$ e $1419 \mathrm{~cm}^{-1}$ $\left(v_{\mathrm{s}}\right)^{38}$. A diferença observada de $139 \mathrm{~cm}^{-1}$ entre $\Delta v_{\mathrm{a}}$ e $\Delta v_{\mathrm{s}}$ é praticamente a mesma encontrada para o benzoato de sódio $\left(136 \mathrm{~cm}^{-1}\right)$. Isto indica a possibilidade dos átomos de oxigênio do grupamento carboxilato realizarem uma ponte entre dois íons magnésio vizinhos. As bandas atribuídas a estiramentos e deformações do anel aparecem em 1599, 1509 e $721 \mathrm{~cm}^{-133,38}$. O espectro no IV também revela que no material existem íons nitrato, pela presença de bandas em 1384, 1305, 1025 e $807 \mathrm{~cm}^{-1}{ }^{26}$, originalmente presentes no sal de magnésio utilizado e que não foram retirados totalmente na lavagem com etanol. Observou-se também a presença de íons carbonato ${ }^{26}$, com bandas em 840 e $678 \mathrm{~cm}^{-1}$, formados provavelmente do $\mathrm{CO}_{2}$ desprendido da hidrólise da uréia. Estudos estão em progresso na tentativa de caracterizar química e estruturalmente a fase obtida. 


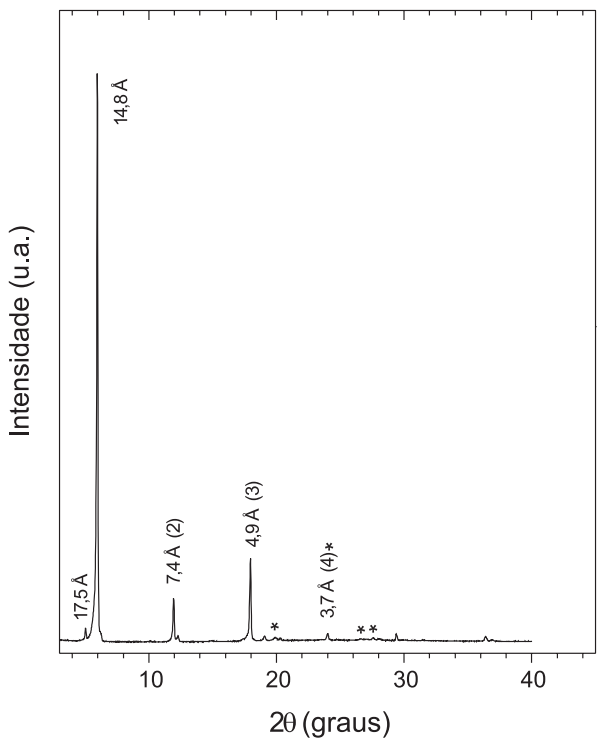

Figura 9. Difratograma de raios-X do produto da fusão do ácido benzóico na presença de uréia e nitrato de magnésio hexaidratado $(*=$ benzoato de magnésio)

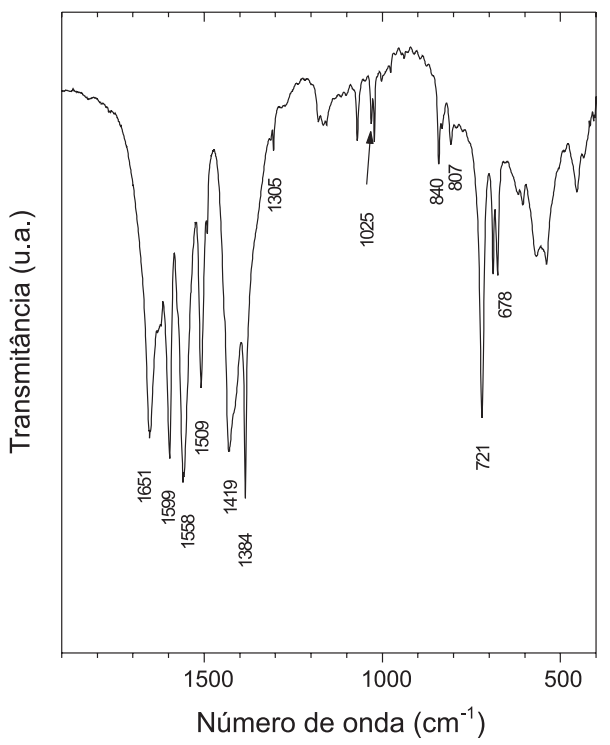

Figura 10. Espectro no IV do produto da fusão do ácido benzóico na presença de uréia e nitrato de magnésio hexaidratado

\section{CONCLUSÕES}

Deve-se evitar o emprego do meio aquoso nas reações de funcionalização com ácido succínico, pois em caso de reação, ocorre hidrólise do produto, regenerando-se a matriz, com conseqüente perda de cristalinidade. A agitação em acetona e isobutanol não é um procedimento adequado para a inserção do íon succinato, pois funcionaliza somente a superfície externa dos cristais de brucita.

Reagindo-se a brucita em condições solvotérmicas, existem sinais de funcionalização das superfícies internas das lamelas, pois um novo composto é produzido com distância basal de 9 Å. Os respectivos espectros de IV mostram que os íons carboxilato estão ligados ao hidróxido de magnésio com maior força que nos materiais obtidos pela técnica de agitação. O incremento no espaçamento corresponde ao diâmetro de uma cadeia alifática (3,9 ̊̊).

Em condições solvotérmicas, a reação em acetona diminui a cristalinidade da brucita em comparação com o isobutanol, enquan- to que nas condições de agitação, é o isobutanol que mais influencia na cristalinidade do mineral.

A precipitação do hidróxido de magnésio em presença de ácido benzóico produz brucita não funcionalizada. A agitação em dimetilsulfóxido não altera o espaçamento basal da brucita. As reações em meio aquoso e estado sólido levam à formação de benzoato de magnésio identificado pelo difratograma de raios-X e, em alguns casos, misturas com a presença de brucita.

A reação de fusão do ácido benzóico na presença de nitrato de magnésio hidratado, uréia e ácido benzóico leva à formação de um composto lamelar com espaçamento basal de 14,8 , cujo padrão de difração de raios-X é diferente do benzoato de magnésio, evidenciando que essa rota pode ser a mais promissora para o processo de funcionalização de brucita com ácidos carboxílicos.

\section{REFERÊNCIAS}

1. Prevot, V.; Forano, C.; Besse, J. P.; Appl. Clay Sci. 2001, 18, 3.

2. Hibino, T.; Jones, W.; J. Mater. Chem. 2001, 11, 1321.

3. Tong, Z.; Shichi, T.; Takagi, K.; Mater. Lett. 2002, 4146, 1.

4. Crepaldi, L; Valim, J. B.; Quim. Nova 1998, 21, 300.

5. Géhin, A.; Ruby, C.; Abdelmoula, M.; Benali, O.; Ghanbaja, J.; Refait, P.; Géhin, J-M. R.; Solid State Sci. 2002, 4, 61.

6. Rajamathi, M.; Kamath, P. V.; Int. J. Inorg. Mater. 2001, 3, 901.

7. Tagaya, H.; Morioka, H.; Kadokawa, J-i.; Karasu, M.; Chiba, K.; Supramol. Sci. 1995, 2, 33.

8. Maeda, K.; Kiyozumi, Y.; Mizukami, F.; Angew. Chem., Int. Ed. 1994, 33, 2335.

9. Ogata, S.; Tagaya, H.; Karasu, M.; Kadokawa, J.; J. Mater. Chem. 2000, 10,321 .

10. Markov, L.; Petrov, K.; Petkov, V.; Thermochim. Acta 1986, 106, 283.

11. Auer, S.; Pöllmann, H.; J. Solid State Chem. 1993, 109, 187.

12. Laget, V.; Drillon, M.; Hornick, C.; Rabu, P.; Romero, F.; Turek, P.; Ziessel, R.; J. Alloys Compd. 1997, 262-263, 423.

13. Rabu, P.; Drillon, M.; Hornick, C.; Analusis 2000, 28, 103.

14. Newmann S. P.; Jones, W.; J. Solid State Chem. 1999, 148, 26.

15. Meyn, M.; Beneke, K.; Lagaly, G.; Inorg. Chem. 1993, 32, 1209.

16. Nishizawa, H.; Yuasa, K.; J. Solid State Chem. 1998, 141, 229.

17. Wypych, F.; Schreiner, W. H.; Marangoni, R.; J. Colloid Interface Sci. 2002, $253,180$.

18. Inoue, M.; Tanino, H.; Kondo, Y.; Inui, T.; Clays Clay Miner. 1991, 39, 151.

19. Isupov, V. P.; J. Struct. Chem. 1999, 40, 672.

20. Vaysse, C.; Guerlou-Demourges, L.; Delmas, C.; Inorg. Chem. 2002, 41, 6905.

21. Aisawa, S.; Takahashi, S.; Ogasawara, W.; Umetsu, Y.; Narita, E.; J. Solid State Chem. 2001, 162, 52

22. Henrist, C.; Mathieu, J.-P.; Vogels, C.; Rulmont, A.; Cloots, R.; J. Cryst. Growth 2003, 249, 321.

23. Data collection of The Joint Committee on Powder Diffraction Standard; PCPDFWIN version 2.2, June 2001. Copyright (C) 2001.

24. Frost, R. L.; Kloprogge. J. T.; Spectrochim. Acta, Part A 1999, 55, 2195.

25. Oliveira de, E. F.; Hase, Y.; Vib. Spectrosc. 2002, 941, 1.

26. Nakamoto, K.; Infrared and raman spectra of inorganic and coordination compounds, $4^{\text {th }}$ ed., Wiley: New York, 1986.

27. Hornick, C.; Rabu, P.; Drillon, M.; Polyhedron 2000, 19, 259.

28. Dutta, P. K.; Robins, D. S.; Langmuir 1994, 10, 1851.

29. Lévy, F.; Physics and chemistry of materials with layered structures. Intercalated Layered Materials, D. Reidel Publishing Company: Netherlands, 1979, vol. 6.

30. Wypych, F.; Arízaga, G. G. C.; Gardolinski, J. E. F. C.; J. Colloid Interface Sci., no prelo.

31. Moggridge, G. D.; Parent, P.; Tourillon, G.; Physica B 1995, 208 \& 209, 269.

32. Meyn, M.; Beneke, K.; Lagaly, G.; Inorg. Chem. 1990, 29, 5201.

33. Hsue, H-B.; Chen, C-Y.; Polymer 2003, 44, 1151.

34. O’Hare, D.; Fogg, A.; Green, V. M.; Harvey, H. G.; Mol. Cryst. Liq. Cryst. 2000, 341, 295.

35. Hyperchem; Release 4.5 for Windows. Hypercube Inc., 1995.

36. Wypych, F.; Schreiner, W. H.; Richard, Jr. E.; J. Colloid Interface Sci. 2004, $276,167$.

37. Carlino, S.; Solid State Ionics 1997, 98, 73.

38. Silverstein, R. M.; Bassler, G. C.; Morril, T. C.; Identificação espectrométrica de compostos orgânicos, $5^{\mathrm{a}}$ ed., Guanabara Koogan: Rio de Janeiro, 1994. 